\title{
Inefficient mapping: the ethical wayfinding potential of drawing while walking
}

Linda Knight

RMIT University, Melbourne, Australia 
This photo essay demonstrates how arts-based methods can translate walking practices into an immanent and ethical research practice. Inefficient mapping brings arts practices and speculative theories together through critical, creative praxis, thereby creating a geontologic methodology for theorizing life in the current ecological crisis. The images convey how mapping the non/in/human while walking, extends awareness of rights, histories, presences and the impacts of settler colonial occupation on lands and inhabitants.

I developed inefficient mapping to visually articulate concepts and ideas embedded in geontologic and speculative theories-particularly Povinelli's (2016) geontologies, Haraway's (2008; 2016) interspecies kin-making, Barad's (2007) ethics of mattering and intraactive entanglements, and Bennett's (2010) vibrant matter-to consider the political, environmental, technological and social impacts on non/in/human lives due to settler colonisation and climate change.

Inefficient mapping is gestural, drawn marking that takes place in situ. The mapping is produced while walking and moving. It is possible to engage technologies such as tabletbased drawing apps. Alternatively, the mapping can be done using paper and conventional drawing tools. In each instance the mappings record affective relations within the milieu. Inefficient mapping ethically entangles with, observes, and 'modestly witnesses' non/in/human lives in spaces in "more corporeal, inflected, and optically dense, if less elegant" ways than via colonial mapping practices (Haraway, 2004, p. 224). The 'inefficient' descriptor accentuates Haraway's immersive, modest witnessing by embracing the potency of partiality. The inefficient descriptor is also ethical and political because its attention to affect resists and challenges the dominance of technocratic/deterministic mapping research methods, their perceived reliability and objectivity, and lack of attention to the non-representational cultural and historical registers that are present.

The premise of the inefficient mapping method is to produce an abstract record of a phenomena or location while the reasons for the mapping are foregrounded in the mind, remaining central throughout the process. Consequently, the mappings are not observational drawings but are theorised, gestural, visual, and partial accounts of a research walk.

There is no step-by-step instruction for creating the maps, except to say a map is created by drawing without looking at the paper or tablet surface. As an example, the map can be generated by holding paper against the body whilst looking up, observing, witnessing, and making marks that trace the movements of the things seen.

The mapping is highly functional to the researcher because it connects and reconnects them to the walk, through activated concepts and ideas, intentions and interests in relation to specific projects and phenomena. Inefficient mapping is an affective methodologic walking practice that promotes ethical wayfaring and wayfinding by making apparent our inconsequentiality in this vast place. 


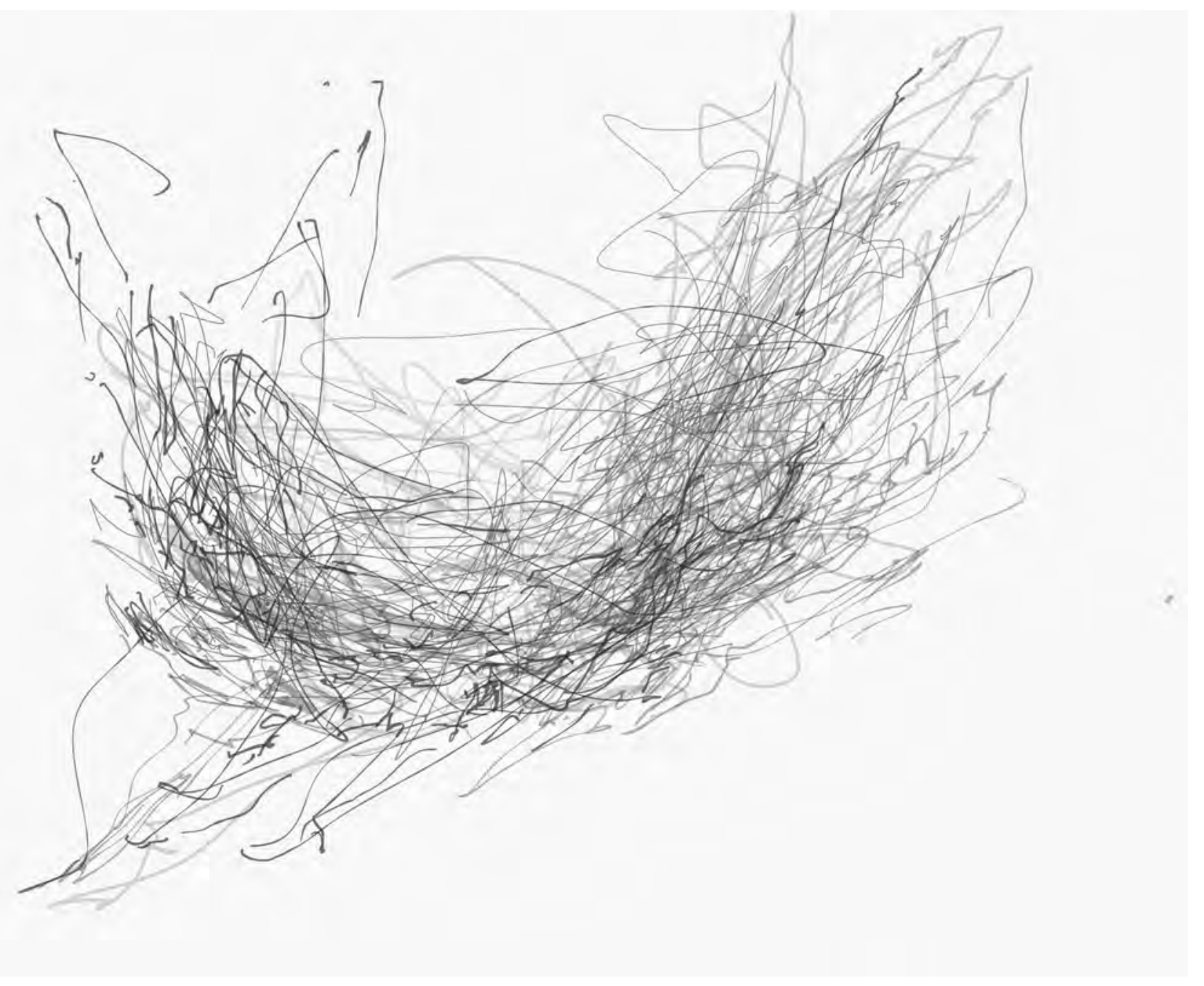

Figure 1: Digital drawing. Photo credit: Linda Knight. 


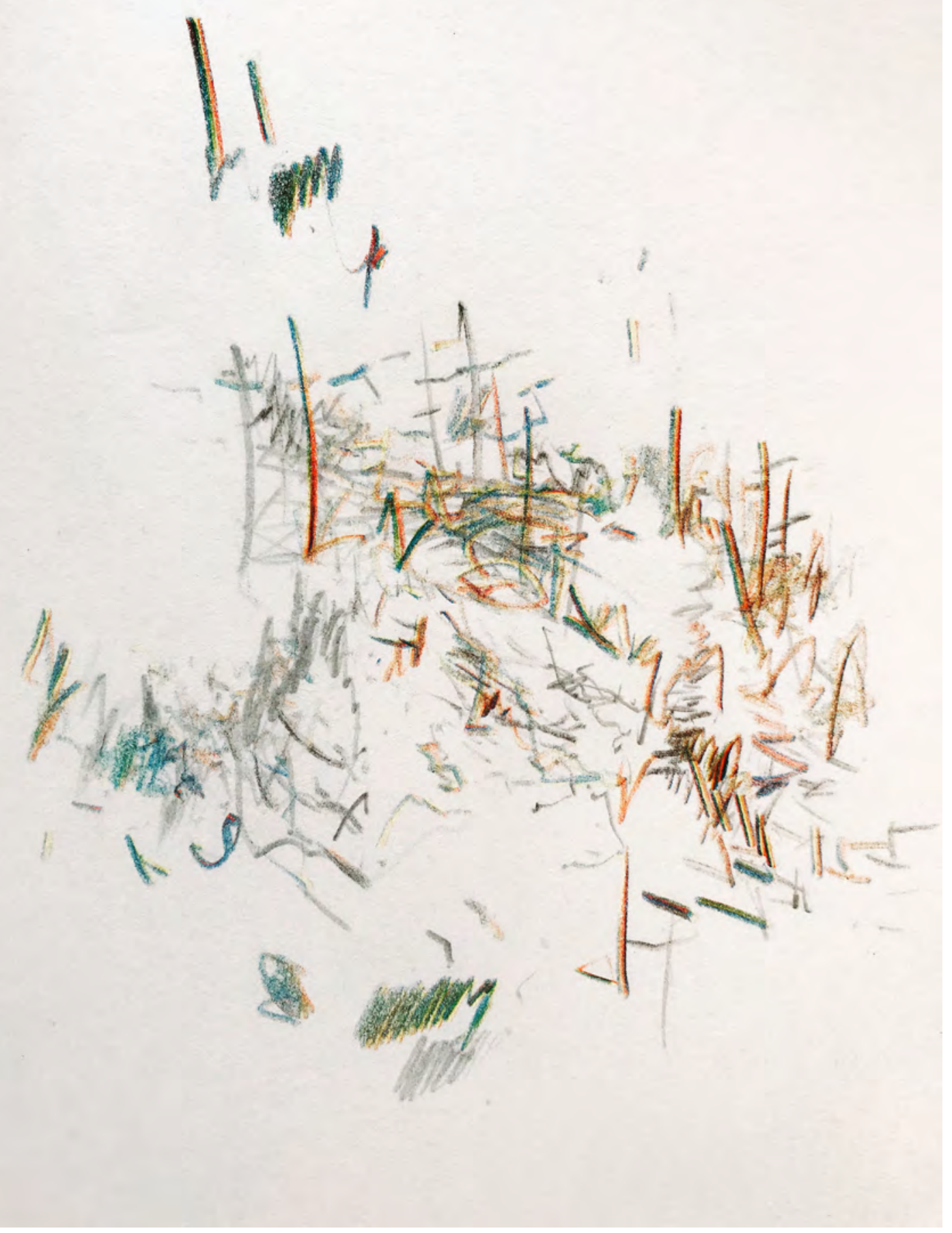

Figure 2: Pencil on paper. Photo credit: Linda Knight. 


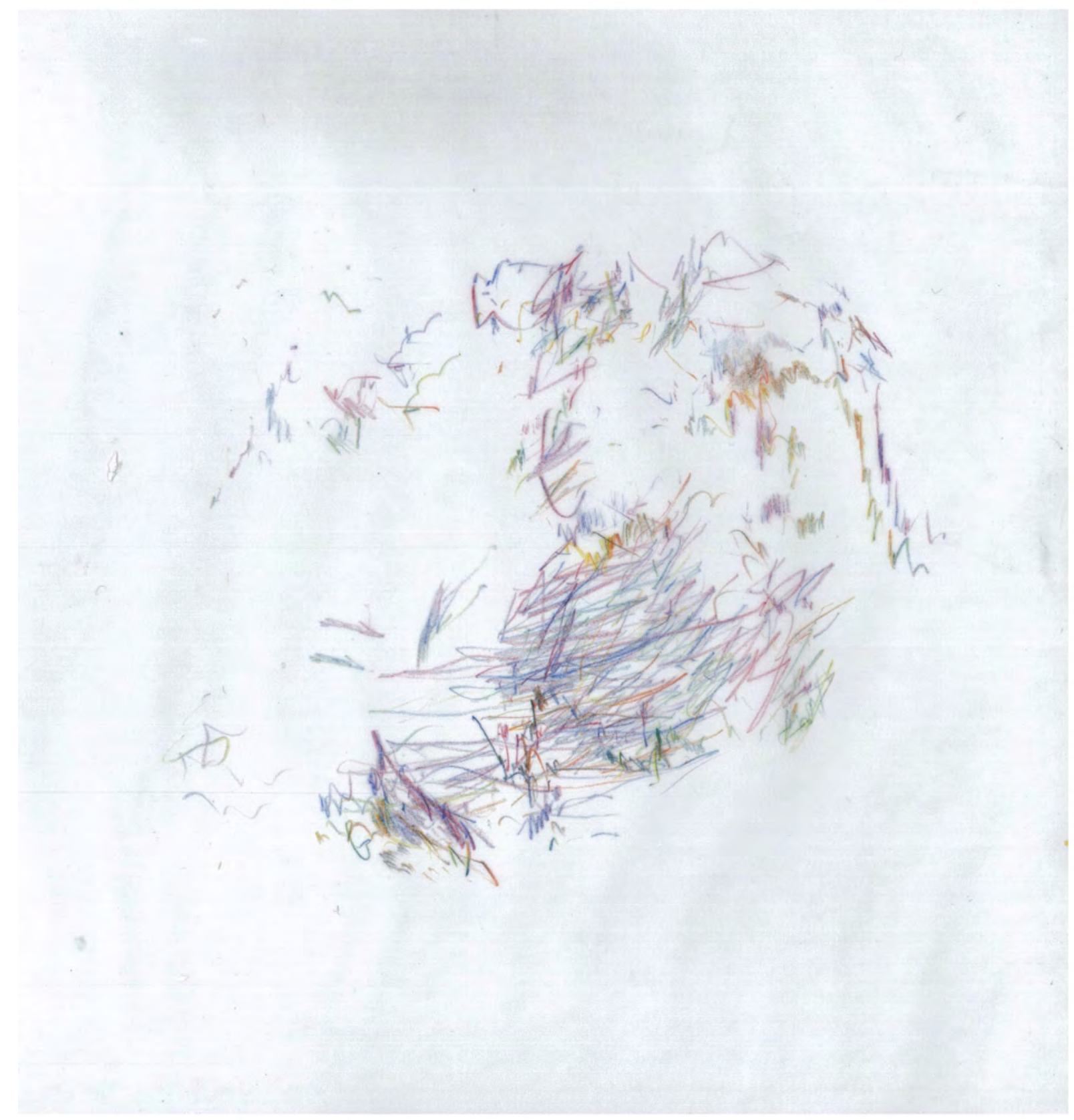

Figure 3: Pencil on tracing film. Photo credit: Linda Knight. 


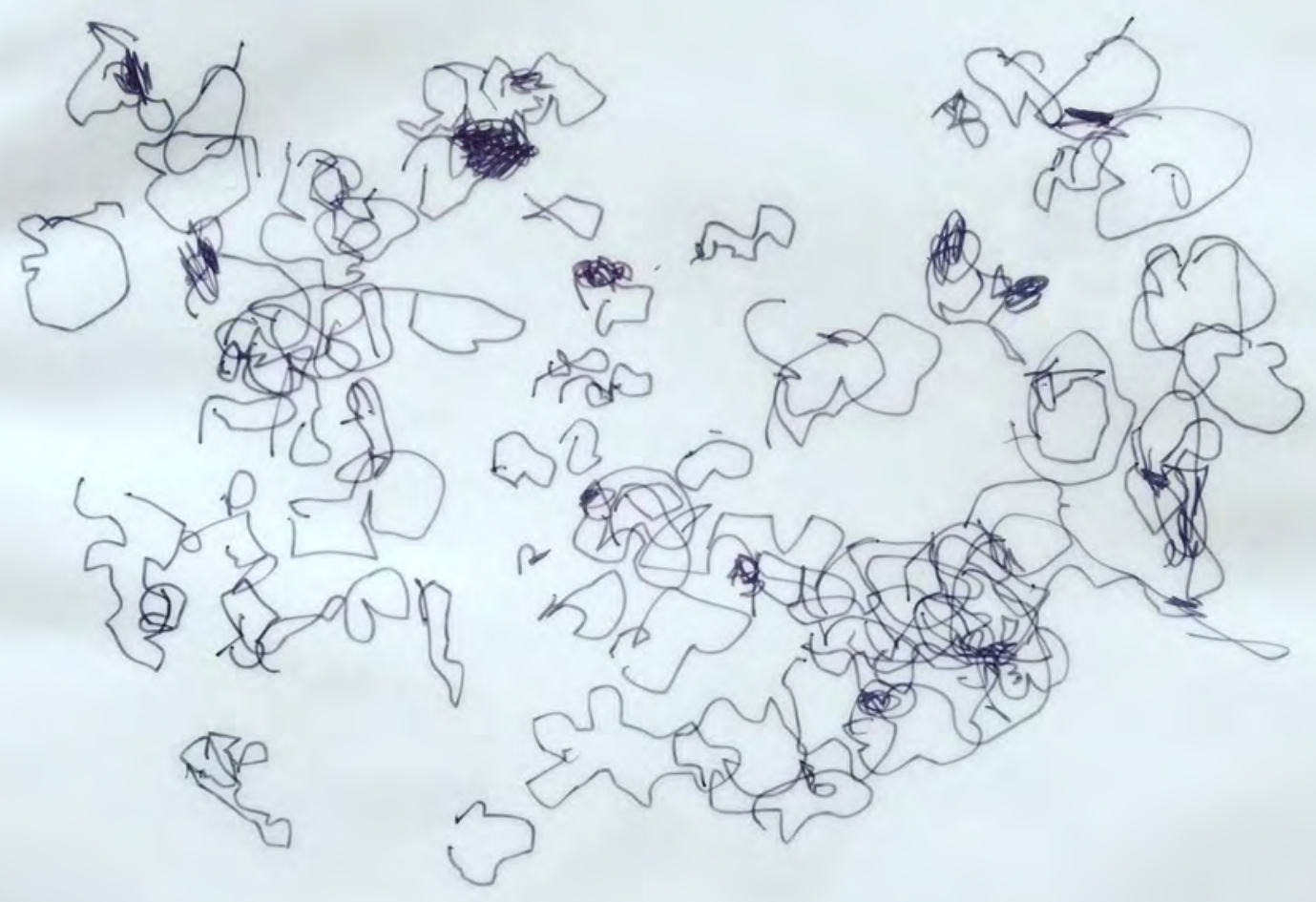

Figure 4: Ink on tracing film. Photo credit: Linda Knight. 


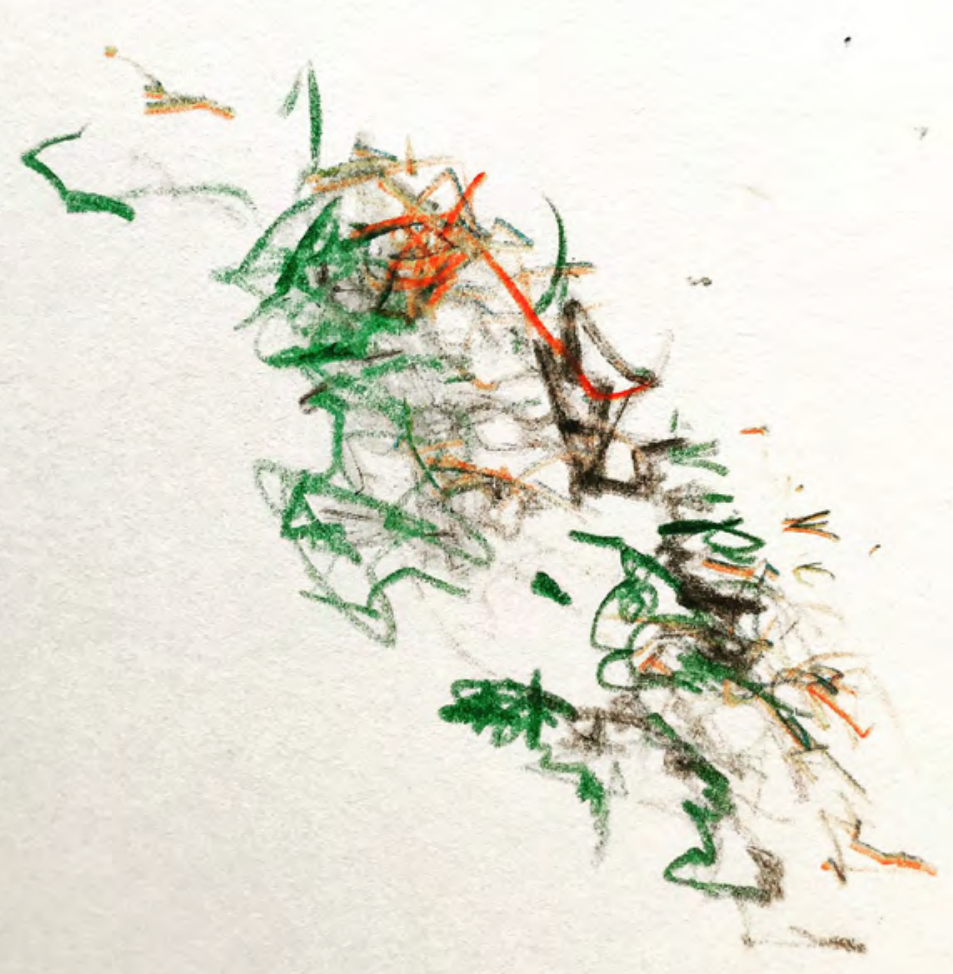

Figure 5: Pencil on paper. Photo credit: Linda Knight. 


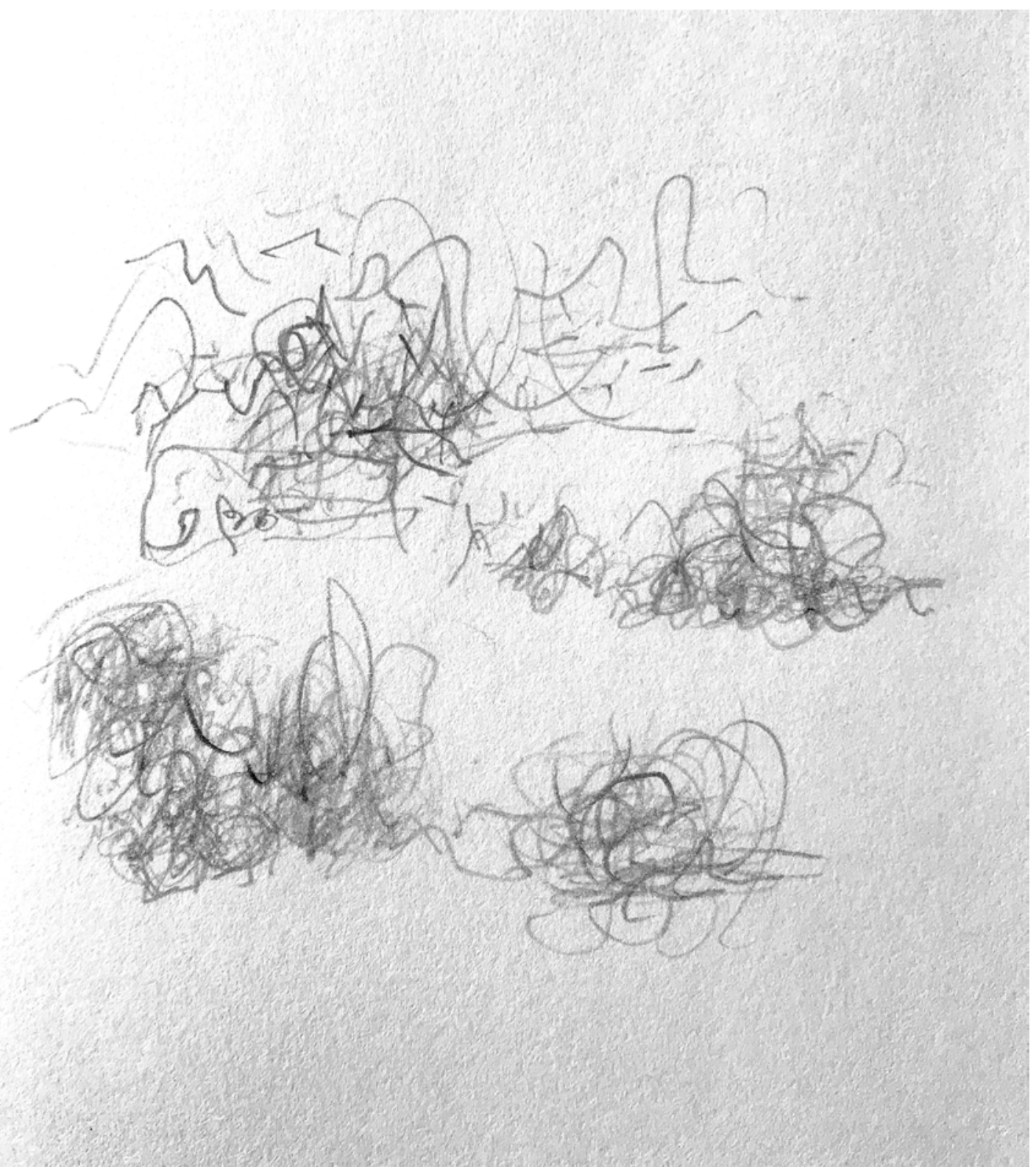

Figure 6: Pencil on paper. Photo credit: Linda Knight. 


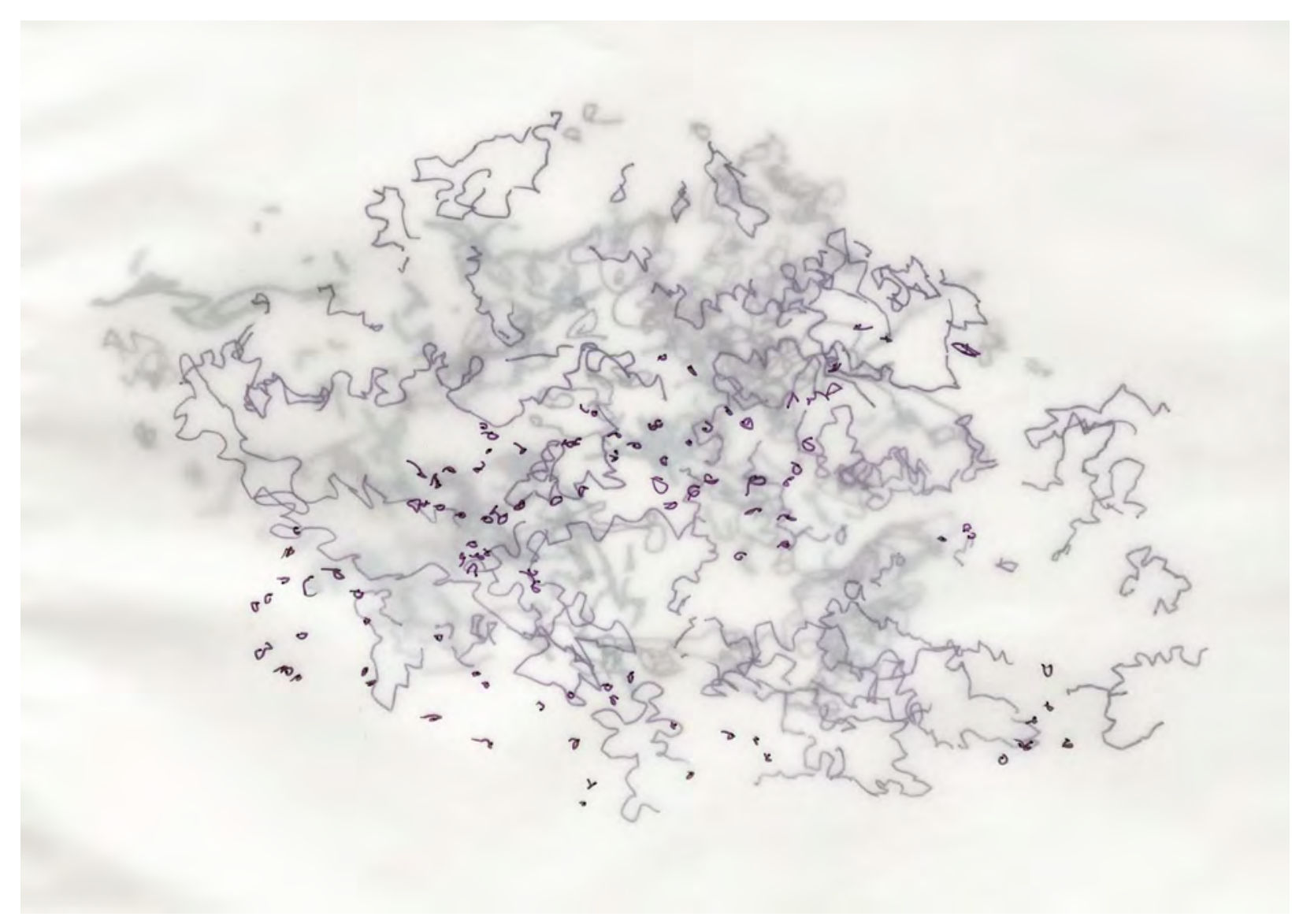

Figure 7: Ink on tracing film. Photo credit: Linda Knight. 


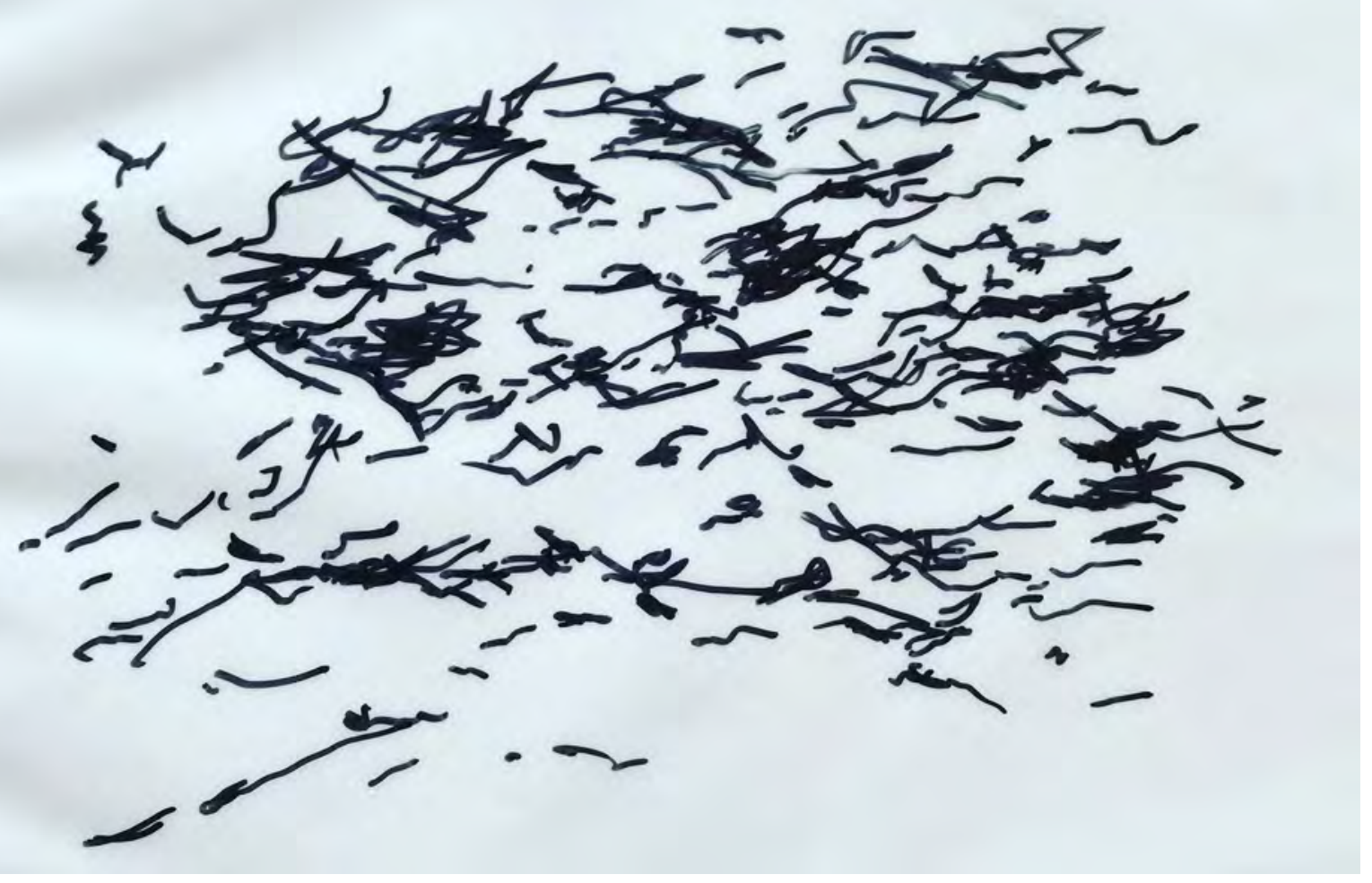

Figure 8: Ink on tracing film. Photo credit: Linda Knight. 


\section{References}

Barad, K. (2007). Meeting the universe halfway: Quantum physics and the entanglement of matter and meaning. Durham, NC: Duke University Press.

Bennett, J. (2010). Vibrant matter: A political ecology of things. Durham, NC: Duke University Press.

Haraway, D. (2004). The Haraway reader. New York, NY: Routledge.

Haraway, D. (2008). When species meet. Minneapolis, MN: University of Minneapolis Press.

Haraway, D. (2016). Staying with the trouble: Making kin in the chthulucene. Durham, NC: Duke University Press.

Povinelli, E. (2016). Geontologies: A requiem to late liberalism. Durham, NC: Duke University Press.

Linda Knight is an artist and academic who uses critical arts practices to speculate on human/non-human/inhuman urban citizenships. Linda created inefficient mapping as a methodologic protocol which she uses to map (play)spaces, and the ethics of urban sites. Linda is also a founding member of \#FEAS - Feminist Educators Against Sexism, a performance arts activist collective that uses irreverence, comedy, and arts interventions to research workplace sexism. Linda has been awarded arts research grants and prizes with international reach and impact; this includes works in exhibitions in Australia, NZ, UK, USA, and Canada. 